\title{
The importance of a large sample cohort for studies on modifier genes influencing disease severity in FAP patients
}

Bente A Talseth-Palmer ${ }^{1,2^{*}}$, Juul T Wijnen ${ }^{3}$, Eva K Andreassen ${ }^{2,4}$, Daniel Barker ${ }^{2,5}$, Shantie Jagmohan-Changur ${ }^{3}$, Carli M Tops ${ }^{3}$, Cliff Meldrum ${ }^{6}$, The Dutch Cancer Genetics Group ${ }^{7}$, Allan Spigelmann ${ }^{8,9,10}$, Frederik J Hes ${ }^{3}$, Tom Van Wezel ${ }^{11}$, Hans FA Vasen ${ }^{12}$ and Rodney J Scott ${ }^{1,2,6}$

\begin{abstract}
Background: Familial adenomatous polyposis (FAP) is usually characterised by the appearance of hundreds-to-thousands of adenomas throughout the colon and rectum and if left untreated the condition will develop into CRC with close to $100 \%$ penetrance. Germline mutations in the APC gene, which plays an integral role in the Wnt-signalling pathway, have been found to be responsible for 70-90\% of FAP cases. Several studies suggest that modifier genes may play an important role in the development of CRC and possible modifiers for FAP have been suggested. Interestingly, a study has found that SNPs within ATP5A1 is associated with raised levels of ATP5A1 expression and high expression levels may facilitate CRC development. We aimed to determine if SNPS in ATP5A1 modify the risk of developing CRC/adenomas in FAP patients.

Methods: Genomic DNA from 139 Australian FAP patients with a germline APC mutation underwent genotyping at the Australian Genome Research Facility (AGRF) utilising iPLEX GOLD chemistry with Sequenom MassArray on an Autoflex Spectrometer for 16 SNPs in the ATP5A1 gene. Association between ages of diagnosis/risk of CRC/adenomas was tested with Kaplan-Meier estimator analysis, logistic regression and cox proportional hazard regression.

Results: An association between age of diagnosis of CRC and genotypes was observed for SNP rs2578189 ( $p=0.0014)$, with individuals harbouring the variant genotype developing CRC 29 years earlier than individuals harbouring the wildtype genotype. Individuals harbouring the variant genotype of SNP rs 2578189 were also at increased risk of CRC $(\mathrm{HR}=13.79,95 \% \mathrm{Cl}=2.36-80.64, p=0.004)$. We used an independent Dutch FAP cohort $(\mathrm{n}=427)$ to validate our results; no association between SNP rs2578189 and CRC was observed.

Conclusion: These results highlight the difficulties in studying a disease that has a high degree of intervention and also emphasize the importance of large sample sizes when searching for modifier genes in patients with an inherited predisposition to disease. To fully determine if there are genetic modifiers of disease in FAP we would encourage people that are interested in collaborating in future studies into the role of modifier genes in disease expression in FAP to join forces.
\end{abstract}

Keywords: Modifier genes, Disease severity, FAP

\footnotetext{
* Correspondence: Bente.Talseth-Palmer@newcastle.edu.au

'School of Biomedical Sciences and Pharmacy, University of Newcastle,

Newcastle, Australia

${ }^{2}$ Hunter Medical Research Institute, John Hunter Hospital, Newcastle,

Australia

Full list of author information is available at the end of the article
} 


\section{Background}

Colorectal cancer (CRC) is one of the most common and preventable forms of cancers worldwide, with an annual incidence of $\sim 16,000$ and accounting for $\sim 4,000$ deaths in Australia alone [1]. Several genetic and environmental factors contribute to the development of cancer and it is estimated that up to $35 \%$ of all CRCs are caused by a genetic predisposition [2]. Familial adenomatous polyposis (FAP) accounts for approximately $1 \%$ of all CRCs [3] and is an inherited autosomal-dominant condition characterised by the appearance of hundreds to thousands of adenomas throughout the colon and rectum [3]. The disease has almost $100 \%$ penetrance and if left untreated will ultimately develop into CRC by the third or fourth decade of life. Extra-colonic manifestation occur in approximately $70 \%$ of FAP patients [4] and include desmoid tumours, congenital hypertrophy of the retinal pigment epithelium (CHRPE), hepatoblastoma, fundic gland polyps, pancreatic and thyroid cancers, dental abnormalities and malignant tumours of the central nervous system $[3,5,6]$.

Truncating germline mutations in the adenomatous polyposis coli $(A P C)$ gene are responsible for $70-90 \%$ of FAP cases [7]. APC plays an integral role in the Wntsignalling pathway, especially in regards to the degradation of $\beta$-catenin within the cell cytoplasm. Considerable variability in disease expression is observed within families and among individuals with identical mutations exist [8] and it has been shown that the greater the number of colorectal adenomas, the greater the CRC risk is [9]. Even though haplotype reconstructions from pedigrees found no evidence for a specific $A P C$ haplotype associated with disease severity [10], genotype-phenotype correlations have been associated with the location of germline mutations within $A P C$ that are related to the severity of polyposis and expression of extra-colonic features [7,11]. Patients with mutations in the mutation cluster region (MCR), located between codons 1286 to 1513 [12], have generally a worse prognosis with earlier onset of disease [13]. Most severe disease is associated with germline mutations at codon 1309 [14], while milder forms of disease with less than 100 adenomas and later ages of onset (attenuated FAP (AFAP)) is associated with codons $<157,312-412$ and $>1595[11,15]$.

Several studies suggest that low-penetrant susceptibility genes may play an important role in the development of sporadic CRC [16-21]. There is evidence to show that variation in FAP severity, which has been shown to be independent of $A P C$ mutation and most likely the action of modifier genes, is expected to result in different rates of tumour initiation (adenoma number) rather than differences in tumour progression i.e. adenomas to carcinoma [22]. Modifier genes can influence individual susceptibility to cancer by enhancing or supressing the initiation, growth and/or progression of tumour cells. The pattern of intrafamilial variation in colonic FAP severity is consistent with the action of modifier genes [10,22-24].

Interestingly, a study has found that the ATP $5 A 1$ gene (chromosome 18q21) may act as a modifier gene in the development of CRC in the murine version of human FAP $\left(A P C^{M i n}\right.$ mice) [25]. The gene has previously been shown to suppress polyp formation in mice when it is mutated, with mutant Atp5a1 mice showing a reduction in small intestinal and colonic polyps by approximately 90\% [26]. Unexpectedly, this mutation has also shown that more adenomas progress to carcinomas in Min mice that carry the Atp5a1 mutation [25]. The ATP5A1 gene encodes the alpha-subunit of ATP synthase, a multi-subunit enzyme which resided on the mitochondrial membrane. Absence of ATP5A1 leads to a nonfunctional $\alpha$-synthesis subunit and subsequent apoptosis of the cell [27]. Raised levels of ATP5A1 expression have been associated with certain single nucleotide polymorphisms (SNPs) and high expression levels together with chromosome instability (CIN) may facilitate CRC development [28]. This study aims to investigate if SNPs in the ATP5A1 gene can act as modifiers for CRC development in FAP patients.

\section{Methods}

\section{Sample cohort}

Genomic DNA from 139 FAP patients from 86 families with a molecular diagnosis of FAP (carriers of germline $A P C$ mutations) was obtained from the Hunter Area Pathology Service (HAPS), John Hunter Hospital, Newcastle, New South Wales, Australia. All samples were collected between the years 1997 and 2008. Each participant $(n=139)$ had previously contributed blood from which DNA was extracted using the salt precipitation method [29]. All the participants in the study have given informed consent for their de-identified DNA to be used for future research into the cause of their condition. Ethics approval was obtained from Hunter Area Research Ethics Committee and the University of Newcastle Human Research Ethics Committee.

\section{Genotyping}

The genotyping was outsourced to the Australian Genome Research Facility (AGRF) who utilised iPLEX GOLD chemistry with Sequenom MassArray on an Autoflex spectrometer to genotype 16 SNPs in ATP5A1 (18q21); rs13381709, rs1800636, rs1800637, rs1800639, rs1800640, rs2298787, rs2578187, rs2578189, rs7244921, rs8088881, rs8089150, rs8092674, rs8093880, rs8094902, rs8095031 and rs8095608.

\section{Statistical analysis}

A Pearson's Chi-square test was used to evaluate deviation from the expected Hardy-Weinberg equilibrium (HWE). 
Fourteen of the sixteen SNPs seemed to be in linkage disequilibrium as 137/139 samples have the exact same genotypes; we are therefore only testing three SNPs and applied Bonferoni correction for multiple testing resulting in a corrected significance threshold of: $p=0.05 / 3=0.0167$. Risk of CRC association with each SNP was estimated by heterozygous and homozygous odds ratio (OR) using simple logistic regression and multiple logistic regressions to adjust for gender (male; female) and mutation group according to severe (APC MCR = codons 1250-1513), attenuated $(\mathrm{APC}$ AFAP $=$ codons $<157,312-412$ and $>1595$ ) and intermediate $(\mathrm{APC}=$ the rest of the gene) polyposis phenotypes. Kaplan-Meier estimator analysis was used to test association between age of diagnosis of CRC and genotypes. Age of diagnoses of CRC were used as estimate functions, while age at last follow up was used for cancer free individuals. Wilcoxon's (Breslow), Log-rank and Tarone-Ware tests were used to examine homogeneity of the Kaplan-Meier plots. All three tests were required to be significant for results to be considered reliable but only log-rank test is reported in Table 1. If a SNP was found to be associated with risk of $\mathrm{CRC}$ /adenomas through logistic regression/Kaplan-Meier, association between genotype and risk of CRC/adenomas was further evaluated using Cox proportional hazard model. Clustering of samples within families were adjusted for by including family as a frailty term in the model, if there was more than one member of a family, patients were grouped together as one 'cluster'.

\section{Validation cohort}

To confirm the significant association observed in the Australian FAP cohort for SNP rs2578189 we recruited an independent Dutch FAP cohort from Leiden University Medical Centre. Genotyping of rs2578189 was outsourced to KBioscience (England, UK) who genotyped 427 FAP patients with a germline $A P C$ mutation from 182 Dutch families with a KASP assay. Due to extensive follow-up and surveillance of this FAP cohort, we were able to divide the patients into two groups, those that developed cancer and those who developed adenomas. Furthermore, we defined AFAP as $<100$ adenomas and Classic FAP as according to the presence of $>100$ adenomas.

\section{Results and discussion}

As cancer development in general is known to be influenced by both genetic and environmental factors, it is important to explore the possibility of different genes being involved in modifying the expression of disease in FAP patients - as patients harbouring identical mutations in $A P C$ can have very different disease profiles that cannot be explained by environmental factors alone. Identification of FAP patients with a modifying genotype is important for the implementation of screening strategies at an early age to remove premalignant adenomas that are likely to be associated with disease development. As it has been suggested that raised levels of ATP5A1 expression have been linked to certain SNPs and high expression levels may facilitate CRC development [28], we aimed to study several SNPs in this gene to determine whether they influence the age of diagnosis or risk of developing CRC.

\section{Association testing between disease severity and ATP5A1}

The genotype frequency distribution for the different SNPs in this study was determined to establish a correlation with disease development in FAP patients. All sixteen SNPs were in Hardy-Weinberg equilibrium (HWE). Genotype frequency of the sixteen SNPs, results of simple logistic regression and Kaplan-Meier analysis can be seen in Table 1. In summary, an association between age of diagnosis of CRC and genotypes can be seen for SNP rs2578189 (Log-rank $p=0.0014$, Wilcoxon $p=0.0004$ and Tarone-Ware $p=0.0009$ ) with individuals harbouring the variant genotype (TT) developing CRC 29 years earlier than patients harbouring the wildtype genotype (CC), median age of diagnosis of CRC is 74 years for genotype CC, 55 years for genotype CT and 45 years for genotype TT. Even though logistic regression did not show a significant influence of this SNP on risk of developing CRC (see Table 1), a multiple logistic regression was performed to adjust for gender and mutation group; a trend towards the variant genotype increasing your risk of CRC was observed $(\mathrm{HR}=7.85,95 \% \mathrm{CI}=0.86-71.89, p=0.068)$, which seems to be influenced by mutation group $(p=0.028)$ and not gender $(p=0.296)$.

Cox proportional hazard regression (adjusted for gender and mutation group) further demonstrates that individuals harbouring the variant genotype of SNP rs2578189 are at higher instantaneous risk (increased hazard) compared to individuals harbouring the wildtype genotype (hazard ratio $(\mathrm{HR})=13.79,95 \% \mathrm{CI}=2.36-80.64, p=0.004)$. Our results indicate that the variant genotype of SNP rs2578189 in the ATP5A1 gene is a possible modifier of cancer development in Australian FAP patients. We therefore recruited an independent Dutch FAP cohort for validation analysis.

\section{Validation studies of the observed association}

The results from the independent Dutch FAP cohort for SNP rs2578189 can be seen in Table 2. The association between age of diagnosis of CRC and SNP rs2578189 genotypes seen in the Australian FAP cohort was not observed in the Dutch FAP cohort. Neither is the increased risk of CRC observed with Cox proportional hazard regression when the variant genotype of SNP rs2578189 is compared to the wildtype genotype: CRC as endpoint of analysis $(\mathrm{HR}=0.91,95 \% \mathrm{CI}=0.15-5.65$, $p=0.915)$ or adenomas as endpoint of analysis $(\mathrm{HR}=0.98$, $95 \% \mathrm{CI}=0.42-2.32, p=0.973)$. 
Table 1 Logistic regression and Kaplan-Meier analysis

\begin{tabular}{|c|c|c|c|c|c|c|c|c|c|c|c|}
\hline \multicolumn{5}{|c|}{ Logistic regression model $(n=139)$} & \multirow[b]{2}{*}{ Adenomas (n) } & \multicolumn{3}{|c|}{ Analysis endpoint - CRC } & \multicolumn{3}{|c|}{ Analysis endpoint - Adenomas } \\
\hline \multicolumn{2}{|c|}{ APT5A1SNP: Genotype } & Total n (\%) & Cancer free $(n)$ & CRC (n) & & OR $(95 \% \mathrm{Cl})$ & $\mathrm{p}$-value & $\begin{array}{l}\text { Kaplan-Meier analysis } \\
\text { p-value* }\end{array}$ & OR $(95 \% \mathrm{Cl})$ & $p$-value & $\begin{array}{c}\text { Kaplan-Meier analysis } \\
\text { p-value* }\end{array}$ \\
\hline \multicolumn{2}{|c|}{ rs13381709: CC } & $59(42)$ & 51 & 8 & 44 & 1.0 & & & 1.0 & & \\
\hline & CT & $57(41)$ & 46 & 11 & 42 & $1.52(0.56-4.12)$ & 0.406 & 0.3183 & $0.95(0.42-2.19)$ & 0.913 & 0.2561 \\
\hline & $\pi$ & $23(17)$ & 22 & 1 & 13 & $0.29(0.03-2.46)$ & 0.256 & & $0.44(0.16-1.22)$ & 0.115 & \\
\hline \multirow[t]{3}{*}{ rs1800636: } & CC & $59(42)$ & 51 & 8 & 44 & 1.0 & & & 1.0 & & \\
\hline & CT & $57(41)$ & 46 & 11 & 42 & $1.52(0.56-4.12)$ & 0.406 & 0.3183 & $0.95(0.42-2.19)$ & 0.913 & 0.2561 \\
\hline & $\pi$ & $23(17)$ & 22 & 1 & 13 & $0.29(0.03-2.46)$ & 0.256 & & $0.44(0.16-1.22)$ & 0.115 & \\
\hline \multirow[t]{3}{*}{ rs1800637: } & $\pi$ & $58(42)$ & 50 & 8 & 44 & 1.0 & & & 1.0 & & \\
\hline & TC & $56(40)$ & 46 & 10 & 41 & $1.36(0.49-3.74)$ & 0.553 & 0.5385 & $0.87(0.37-2.02)$ & 0.746 & 0.2362 \\
\hline & $\mathrm{CC}$ & $25(18)$ & 23 & 2 & 14 & $0.54(0.11-2.76)$ & 0.462 & & $0.40(0.15-1.09)$ & 0.074 & \\
\hline \multirow[t]{3}{*}{ rs1800639: } & GG & $59(42)$ & 51 & 8 & 44 & 1.0 & & & 1.0 & & \\
\hline & GT & $57(41)$ & 46 & 11 & 42 & $1.52(0.56-4.12)$ & 0.406 & 0.3183 & $0.95(0.42-2.19)$ & 0.913 & 0.2561 \\
\hline & $\pi$ & $23(17)$ & 22 & 1 & 13 & $0.29(0.03-2.46)$ & 0.256 & & $0.44(0.16-1.22)$ & 0.115 & \\
\hline \multirow[t]{4}{*}{ rs1800640: } & $\pi$ & $57(41)$ & 49 & 8 & 44 & 1.0 & & & 1.0 & & \\
\hline & TC & $57(41)$ & 46 & 11 & 42 & $1.52(0.56-1.12)$ & 0.406 & 0.3183 & $0.95(0.42-2.19)$ & 0.913 & 0.2561 \\
\hline & CC & $23(17)$ & 22 & 1 & 13 & $0.29(0.03-2.46)$ & 0.256 & & $0.44(0.16-1.22)$ & 0.115 & \\
\hline & Failed genotyping & $2(1)$ & & & & & & & & & \\
\hline \multirow[t]{3}{*}{ rs2298787: } & $\pi$ & $57(41)$ & 50 & 7 & 42 & 1.0 & & & 1.0 & & \\
\hline & TC & $59(42)$ & 47 & 12 & 44 & $1.82(0.66-5.03)$ & 0.245 & 0.3208 & $1.05(0.46-2.41)$ & 0.913 & 0.4143 \\
\hline & $\mathrm{CC}$ & $23(17)$ & 22 & 1 & 13 & $0.32(0.04-2.80)$ & 0.306 & & $0.46(0.17-1.28)$ & 0.138 & \\
\hline \multirow[t]{3}{*}{ rs2578187: } & GG & $114(82)$ & 99 & 15 & 78 & 1.0 & & & 1.0 & & \\
\hline & GA & $24(17)$ & 19 & 5 & 20 & $1.74(0.56-5.35)$ & 0.336 & 0.9719 & $2.31(0.74-7.24)$ & 0.152 & 0.5744 \\
\hline & AA & $1(1)$ & 1 & 0 & 1 & - & - & & - & - & \\
\hline \multirow[t]{3}{*}{ rs2578189: } & $\mathrm{CC}$ & $89(64)$ & 78 & 11 & 67 & 1.0 & & & 1.0 & & \\
\hline & CT & $45(32)$ & 38 & 7 & 28 & $1.31(0.47-3.64)$ & 0.609 & 0.0014 & $0.54(0.25-1.17)$ & 0.118 & 0.3898 \\
\hline & $\pi$ & $5(4)$ & 3 & 2 & 4 & $4.73(0.71-31.52)$ & 0.109 & & $1.31(0.14-12.38)$ & 0.812 & \\
\hline \multirow[t]{3}{*}{ rs7244921: } & $\pi$ & $59(42)$ & 51 & 8 & 44 & 1.0 & & & 1.0 & & \\
\hline & TC & $57(41)$ & 46 & 11 & 42 & $1.52(0.56-4.12)$ & 0.406 & 0.3183 & $0.95(0.42-2.19)$ & 0.913 & 0.2561 \\
\hline & CC & $23(17)$ & 22 & 1 & 13 & $0.29(0.03-2.46)$ & 0.256 & & $0.44(0.16-1.22)$ & 0.115 & \\
\hline \multirow[t]{3}{*}{ rs8088881: } & $\pi$ & $58(42)$ & 50 & 8 & 44 & 1.0 & & & 1.0 & & \\
\hline & TC & $57(41)$ & 46 & 11 & 42 & $1.49(0.55-4.04)$ & 0.429 & 0.3179 & $0.89(0.38-2.07)$ & 0.788 & 0.2493 \\
\hline & CC & $23(17)$ & 22 & 1 & 13 & $0.28(0.03-2.41)$ & 0.249 & & $0.41(0.15-1.15)$ & 0.090 & \\
\hline
\end{tabular}


Table 1 Logistic regression and Kaplan-Meier analysis (Continued)

\begin{tabular}{|c|c|c|c|c|c|c|c|c|c|c|c|}
\hline & Failed genotyping & $1(1)$ & & & & & & & & & \\
\hline \multirow[t]{3}{*}{ rs8089150: } & $\mathrm{AA}$ & $57(41)$ & 50 & 7 & 42 & 1.0 & & & 1.0 & & \\
\hline & $A G$ & $59(42)$ & 47 & 12 & 44 & $0.82(0.66-5.03)$ & 0.245 & 0.3208 & $1.05(0.46-2.41)$ & 0.913 & 0.4143 \\
\hline & GG & $23(17)$ & 22 & 1 & 13 & $0.32(0.04-2.80)$ & 0.306 & & $0.46(0.17-1.28)$ & 0.138 & \\
\hline \multirow[t]{3}{*}{ rs8092674: } & CC & $59(42)$ & 51 & 8 & 44 & 1.0 & & & 1.0 & & \\
\hline & $\mathrm{CT}$ & $57(41)$ & 46 & 11 & 42 & $1.52(0.56-4.12)$ & 0.406 & 0.3183 & $0.95(0.42-2.19)$ & 0.913 & 0.2561 \\
\hline & $\pi$ & $23(17)$ & 22 & 1 & 13 & $0.29(0.03-2.46)$ & 0.256 & & $0.44(0.16-1.22)$ & 0.115 & \\
\hline \multirow[t]{4}{*}{ rs8093880: } & $\mathrm{CC}$ & $57(41)$ & 49 & 8 & 43 & 1.0 & & & 1.0 & & \\
\hline & $\mathrm{CT}$ & $55(40)$ & 45 & 10 & 42 & $1.36(0.49-3.75)$ & 0.551 & 0.3322 & $1.05(0.44-2.50)$ & 0.909 & 0.3575 \\
\hline & $\pi$ & $23(17)$ & 22 & 1 & 13 & $0.28(0.03-2.36)$ & 0.241 & & $0.42(0.15-1.18)$ & 0.099 & \\
\hline & Failed genotyping & $4(3)$ & & & & & & & & & \\
\hline \multirow[t]{3}{*}{ rs8094902: } & $\pi$ & $59(42)$ & 51 & 8 & 44 & 1.0 & & & 1.0 & & \\
\hline & TC & $57(41)$ & 46 & 11 & 42 & $1.52(0.56-4.12)$ & 0.406 & 0.3183 & $0.95(0.42-2.19)$ & 0.913 & 0.2561 \\
\hline & CC & $23(17)$ & 22 & 1 & 13 & $0.29(0.03-2.46)$ & 0.256 & & $0.44(0.16-1.22)$ & 0.115 & \\
\hline \multirow[t]{4}{*}{ rs8095031: } & $\pi$ & $59(42)$ & 51 & 8 & 44 & 1.0 & & & 1.0 & & \\
\hline & TC & $57(41)$ & 46 & 11 & 42 & $1.52(0.56-4.12)$ & 0.406 & 0.3234 & $0.95(0.42-2.19)$ & 0.913 & 0.2221 \\
\hline & CC & $22(16)$ & 22 & 1 & 12 & $0.30(0.04-2.58)$ & 0.275 & & $0.41(0.15-1.14)$ & 0.087 & \\
\hline & Failed genotyping & $1(1)$ & & & & & & & & & \\
\hline \multirow[t]{4}{*}{ rs8095608: } & $\mathrm{AA}$ & $58(42)$ & 51 & 7 & 43 & 1.0 & & & 1.0 & & \\
\hline & $A G$ & $58(42)$ & 46 & 12 & 43 & $1.90(0.68-5.24)$ & 0.214 & 0.3183 & $1.0(0.44-2.30)$ & 1.000 & 0.3738 \\
\hline & GG & $22(16)$ & 21 & 1 & 12 & $0.35(0.04-2.99)$ & 0.336 & & $0.42(0.15-1.17)$ & 0.096 & \\
\hline & Failed genotyping & $1(1)$ & & & & & & & & & \\
\hline
\end{tabular}

Demographics of the genotype frequencies in Australian FAP patients with CRC, patients with adenomas and cancer/adenoma free individuals. Logistic regression model was used to test risk of CRC associated with each SNP, while Kaplan-Meier estimator analysis was used to test association between age of diagnosis of CRC/adenomas and genotype. Two different analysis was performed; one using CRC as endpoint of analysis and one using adenomas as endpoint of analysis. 
Table 2 Logistic regression and Kaplan-Meier analysis

\begin{tabular}{|c|c|c|c|c|c|c|c|c|c|c|}
\hline \multicolumn{4}{|c|}{ Logistic regression model $(n=423)$} & \multirow[b]{2}{*}{ Adenomas (n) } & \multicolumn{3}{|c|}{ Analysis endpoint - CRC } & \multicolumn{3}{|c|}{ Analysis endpoint - Adenomas } \\
\hline APT5A1SNP: Genotype & Total n (\%) & Cancer free $(n)$ & CRC (n) & & OR $(95 \% \mathrm{Cl})$ & p-value & $\begin{array}{c}\text { Kaplan-Meier } \\
\text { analysis p-value* }\end{array}$ & OR $(95 \% \mathrm{Cl})$ & p-value & $\begin{array}{c}\text { Kaplan-Meier } \\
\text { analysis p-value* }\end{array}$ \\
\hline rs2578189: CC & $325(77)$ & 287 & 38 & 313 & 1.0 & & & 1.0 & & \\
\hline $\mathrm{CT}$ & $89(21)$ & 81 & 8 & 87 & $0.75(0.33-1.66)$ & 0.473 & 0.8739 & $1.53(0.33-70.3)$ & 0.585 & 0.5916 \\
\hline$\pi$ & $9(2)$ & 7 & 2 & 8 & $2.16(0.43-10.77)$ & 0.348 & & $0.28(0.03-2.45)$ & 0.250 & \\
\hline
\end{tabular}

*Log-Rank p-value.

Demographics of the genotype frequencies in Dutch FAP patients with CRC, patients with adenomas, and cancer/adenoma free individuals. Logistic regression model was used to test risk of CRC associated with each SNP, while Kaplan-Meier estimator analysis was used to test association between age of diagnosis of CRC/adenomas and genotype. Two different analyses were performed; one using CRC as endpoint of analysis and one using adenomas as endpoint of analysis. 
The biggest difference between the Australian and Dutch FAP cohort is the extensive follow-up data from the Netherlands about adenoma counts and surgical intervention (284/427 Dutch patients have had surgery). As surgery does not fully protect against CRC and adenomacategory and mutation group are known to influence disease development, we added these confounding factors as co-variats (plus gender as this was done for the Australian cohort) in the Cox proportional hazard regression model for SNP rs2578189 but this did not change the outcome of the analysis (CRC as endpoint of analysis; $\mathrm{HR}=0.65$, 95\% CI $=0.11-3.98, p=0.639$ or adenomas as endpoint of analysis; $\mathrm{HR}=0.96,95 \% \mathrm{CI}=0.41-2.28, p=0.929)$.

\section{Validation cohort - disease expression}

As shown before [7-9,11], phenotypic variability exists within families with FAP suggesting that beside the $A P C$ genotype other factors also play a role in determining the severity of polyposis and risk of CRC for FAP patients. Even though no significant difference can be seen between age of diagnosis of adenomas and adenoma phenotype (AFAP vs. Classic FAP; log-rank $p=0.892$, see Figure 1), the risk of CRC could still be influenced by the number of adenomas. We observed a significant difference between age of diagnosis of CRC and adenoma phenotype, see Figure 2 (Log-rank $p=0.0256$, Wilcoxon $p=0.0083$ and Tarone-Ware $p=0.0124)$, with individuals developing more adenomas (Classic FAP, 100 or more adenomas) developing CRC earlier than AFAP ( $<100$ adenomas). Logistic regression shows that individuals with Classic FAP phenotype are at increased risk of CRC compared to AFAP phenotype; $\mathrm{OR}=2.12,95 \% \mathrm{CI}=1.14-3.92$,

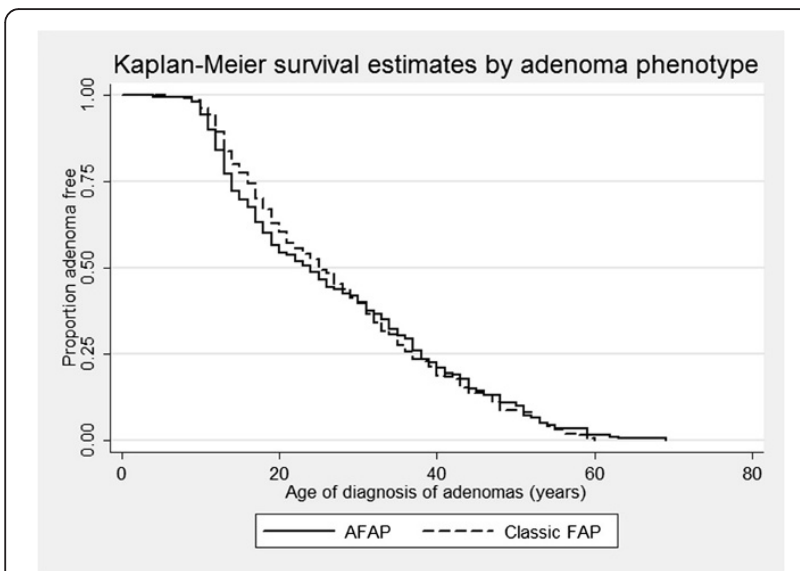

Figure 1 Kaplan-Meier estimated by adenoma phenotype using adenomas as end-point of analysis. The graph shows the effect the adenoma phenotype has on age of diagnosis of adenomas in Dutch FAP patients. The adenoma-categories are: AFAP $=<100$ adenomas and Classic FAP $=100$ or more adenomas. No significant difference can be seen between adenoma phenotype AFAP (24 years) and Classic FAP (25 years); Log-rank $p=0.8923$.

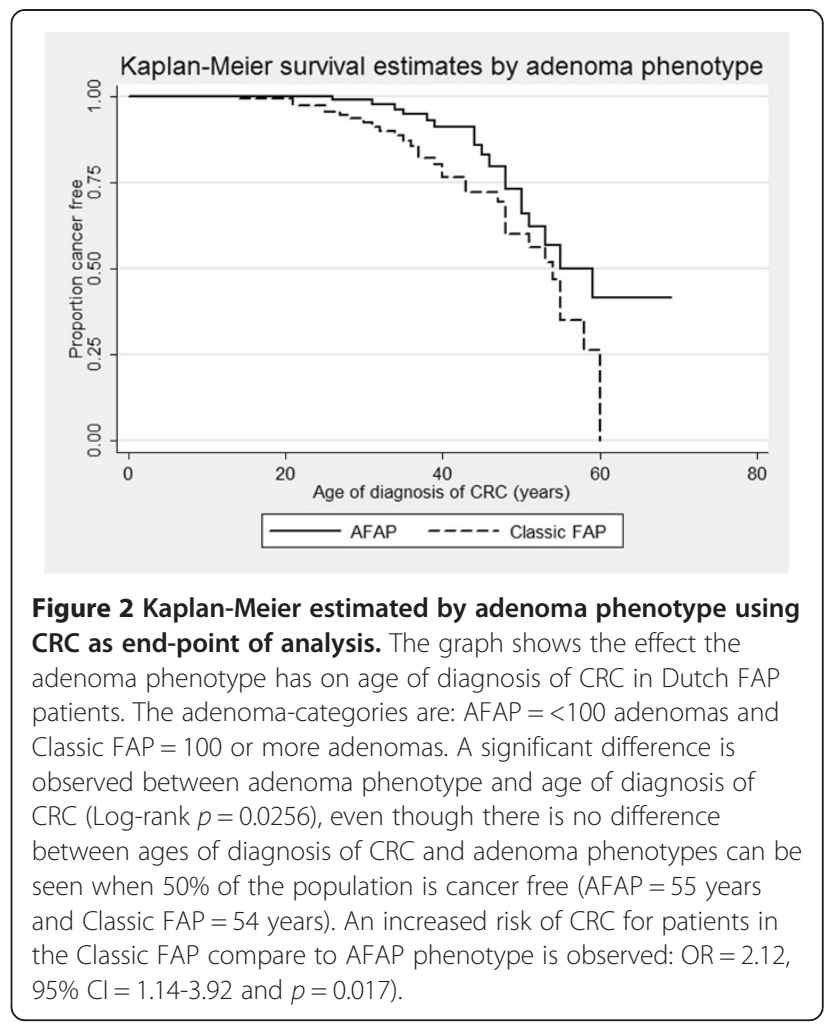

$p=0.017$. This is in accordance with previously reported results where an increased risk of CRC and earlier ages of diagnosis is associated with greater number of adenomas $[9,11,22]$. We also adjusted this analysis according to gender, surgery and mutation group of the patients, as this are all confounding factors that can possibly influence an individual's risk of developing CRC. Multiple logistic regression model did not display an increased risk of CRC $(\mathrm{OR}=0.90,95 \% \mathrm{CI}=0.46-1.77, p=0.764)$, but shows that patients who have had interventional surgery are at increased risk of $\mathrm{CRC}(\mathrm{OR}=14.83,95 \% \mathrm{CI}=3.34-65.91$ and $p \leq 0.001$ ) indicating that one adenoma phenotype has had more surgery than the other group, which is correct as $94 \%$ of Classic FAP patients have had surgery vs. $42 \%$ of AFAP patients. Simple $(\mathrm{HR}=1.78,95 \% \mathrm{CI}=0.88-3.62$, $p=0.107)$ and multiple ( $\mathrm{HR}=1.14,95 \% \mathrm{CI}=0.56-2.35$, $p=0.706)$ Cox proportional hazard regression similarly display no significant increased risk of CRC according to adenoma phenotype, but again demonstrates that surgical intervention $(p=0.015)$ are a marker for the more severe polyposis phenotype (Classic FAP). This is also the case for mutation group; APC MCR $(p \leq 0.001)$.

The severity of polyposis and early onset CRC is dependent on the location of $A P C$ mutations $[7,13]$. The Dutch FAP patients with mutations in the APC MCR develops CRC 13 years earlier than patients with mutations in the rest of the $A P C$ gene, while patients with mutations in APC AFAP regions develops CRC later 
compared to individuals with mutations in the rest of the $A P C$ gene $(\log$-rank $p \leq 0.0001$, see Figure $3 \mathrm{~A})$. The same is observed when adenomas is used as endpoint of analysis with patients developing adenomas at ages; APC $\mathrm{AFAP}=35$ years, $\mathrm{APC}=24$ years and $\mathrm{MCR}=15$ years ( $\log$-rank $p \leq 0.0001$, see Figure $3 \mathrm{~B})$. Cox proportional hazard regression also shows an increased risk of CRC and adenomas for patients with mutations in APC MCR compared to patients with mutations in the rest of the $A P C$ gene (APC mutation category): CRC ( $\mathrm{HR}=7.35,95 \%$ $\mathrm{CI}=2.44-22.14$ and $p \leq 0.001)$ and adenomas $(\mathrm{HR}=2.36$, 95\% CI $=1.54-3.61$ and $p \leq 0.001)$. We also adjusted this analysis for gender, surgery and adenoma phenotype - the results are still significant; $\mathrm{CRC}(\mathrm{HR}=7.71,95 \% \mathrm{CI}=2.53$ 23.49 and $p \leq 0.001)$ and adenomas $(\mathrm{HR}=2.71,95 \%$ $\mathrm{CI}=1.72-4.29$ and $p \leq 0.001)$ and are influenced by whether the patients have had surgery (CRC $p=0.015$ and adenomas $p \leq 0.001)$, not gender (CRC $p=0.869$ and adenomas $p=0.923$ ) or adenoma phenotype (CRC $p=0.706$ and adenomas $p=0.055$ ). Not surprisingly, this is showing us that interventional surgery is the biggest marker for patients with mutations in APC MCR and are therefore at higher risk of CRC. As expected, a decreased risk of CRC and adenomas is observed for patients with mutations in

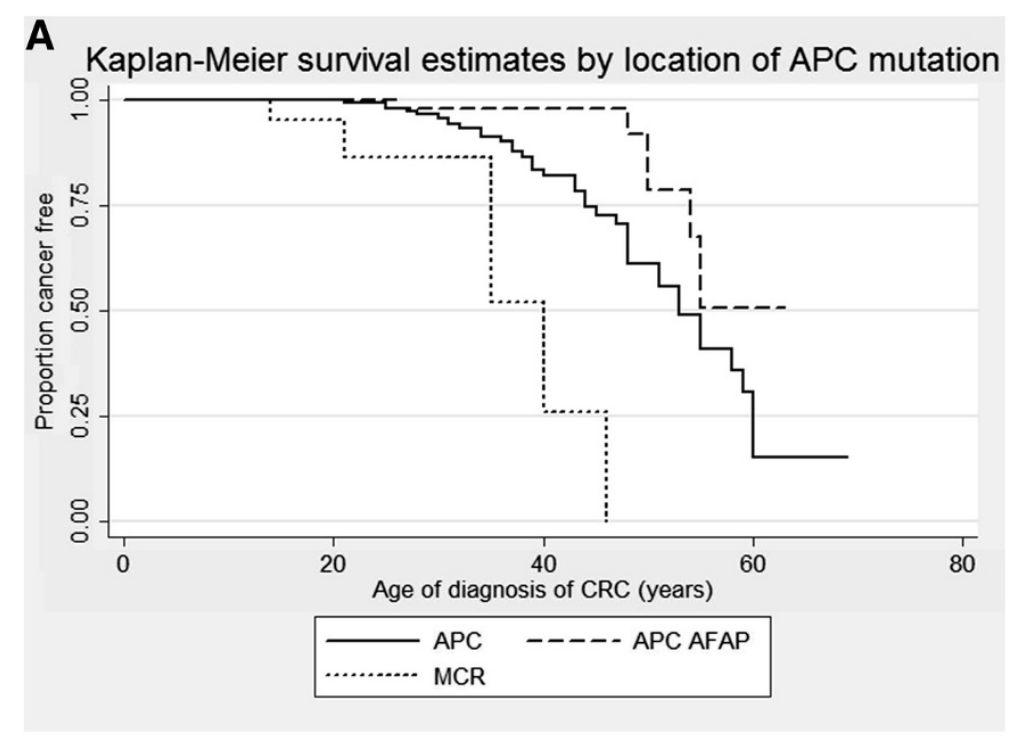

B Kaplan-Meier survival estimates by location of APC mutation

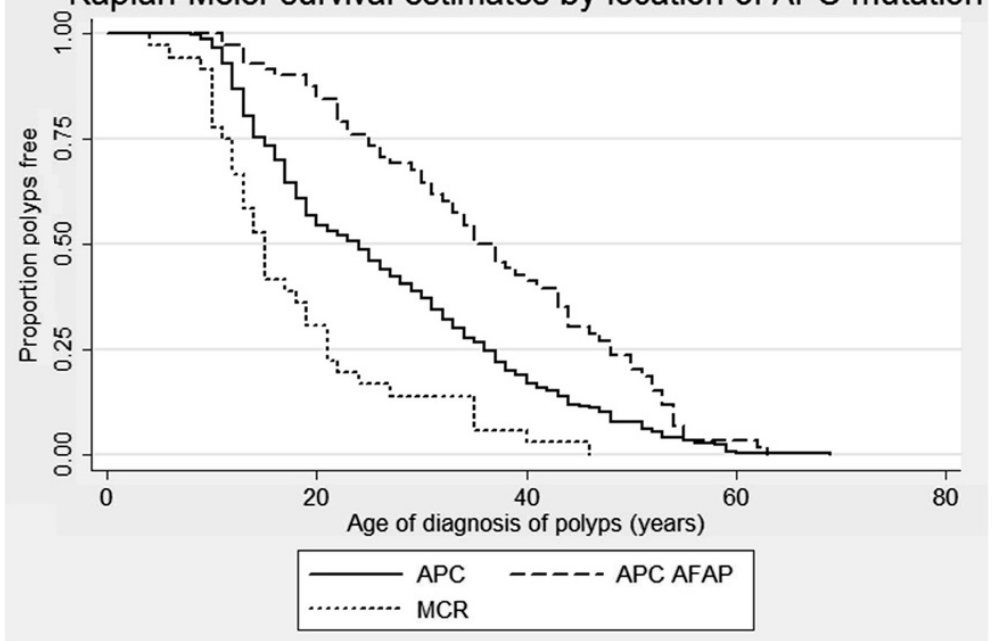

Figure 3 Kaplan-Meier estimated by location of APC mutation. A) Using CRC as end-point of analysis: The graph shows the effect the location of the APC mutation has on age of diagnosis of CRC in Dutch FAP patients. A significant difference is observed between the attenuated (APC AFAP), intermediate (APC, 53 years) and severe (MCR, 40 years) polyposis phenotype; Log-rank $p \leq 0.0001$. B) Using adenomas as end-point of analysis: The graph shows the effect the location of the APC mutation has on age of diagnosis of adenomas in Dutch FAP patients. A significant difference is observed between the attenuated (APC AFAP, 35 years), intermediate (APC, 24 years) and severe (MCR, 15 years) polyposis phenotype; Log-rank $p \leq 0.0001$. 
APC AFAP regions compared to patients with mutations in the rest of the $A P C$ gene: $\mathrm{CRC}(\mathrm{HR}=0.28,95 \%$ $\mathrm{CI}=0.10-0.78$ and $p=0.015)$ and adenomas $(\mathrm{HR}=0.49$, 95\% CI $=0.33-0.73$ and $p \leq 0.001$ ).

The risk of developing CRC in FAP patients is considerably different from the most common genetic predisposition to CRC, Lynch syndrome, with earlier ages of disease onset and close to $100 \%$ penetrance if left untreated. Lynch syndrome cases that are not under surveillance are usually identified when they present with CRC whereas FAP patients initially present with adenomas that are removed before the development of CRC and often undergo total colectomy to reduce the risk of cancer development. The timing of surgery may have influenced adenoma counts such that some patients may have, if left untreated, developed many more adenomas than that identified at colectomy. For this reason, it is much more difficult to study CRC risk and differences in the phenotypic expression in FAP patients as many of them will have interventional surgery to reduce their risk of developing CRC. This could possibly explain the differences observe between the Dutch and Australian patient data, as we have access to extensive follow-up and surveillance data from the Dutch FAP patients that are not available for the Australian patients.

Atp5a1 in mice is located on the same chromosome as $A p c$, linked in the cis configuration on chromosome 18. The modifier locus acts in a dominant fashion to markedly reduce intestinal polyp multiplicity in mice with $A p c$ mutations [26]. One of the reasons why we cannot conclusively associate ATP5A1 in FAP patients with adenoma counts or disease risk could be that in humans $A P C$ is located on chromosome 5, while ATP5A1 is located on chromosome 18.

\section{Conclusion}

These results highlight the difficulties in studying a disease that has a high degree of intervention and also emphasize the importance of large sample sizes when searching for modifier genes in patients with an inherited predisposition to disease. To fully determine if there are genetic modifiers of disease in FAP we would encourage people that are interested in collaborating in future studies into the role of modifier genes in disease expression in FAP to join forces. Even though we were not able to associate SNPs of ATP5A1 with FAP, there remains the possibility that there are genetic modifiers that influence disease severity in FAP due to the differences observed in disease expression.

\section{Competing interests}

The authors declare that they have no competing interests.

\section{Authors' contributions}

BTP: Study design; acquisition of data; analysis and interpretation of data; drafting of the manuscript; statistical analysis. JTW: Acquisition of data; analysis and interpretation of data; critical revision of the manuscript for important intellectual content; technical support; obtained funding; study supervision. EKA: Acquisition of data; analysis and interpretation of data. DB: Statistical advice; analysis and interpretation of data. SJC: Acquisition of data. CMT: Acquisition of data; material support. CM: Acquisition of data; material support. The Dutch Cancer Genetics Group: Patient collection. AS: Patient collection; material support. FJH: Acquisition of data; critical revision of the manuscript for important intellectual content. TWW: Acquisition of data; critical revision of the manuscript for important intellectual content. HFAV: Study concept and design; critical revision of the manuscript for important intellectual content. RJS: Study concept and design; critical revision of the manuscript for important intellectual content; obtained funding; study supervision. All authors read and approved the final manuscript.

\section{Acknowledgements}

This study was supported by grants from Priority Research Centre for Bioinformatics, Biomarker Discovery and Information-Based Medicine, University of Newcastle, Australia; Hunter Medical Research Institute; Dutch Cancer Society KWF 2005-3247; and KWF 2012-5542.

\section{Author details}

${ }^{1}$ School of Biomedical Sciences and Pharmacy, University of Newcastle, Newcastle, Australia. ${ }^{2}$ Hunter Medical Research Institute, John Hunter Hospital, Newcastle, Australia. ${ }^{3}$ Department of Human and Department of Clinical Genetics, Leiden University Medical Centre, Leiden, the Netherlands. ${ }^{4}$ Department of Pharmacology, The Institute of Pharmacy, Faculty of Medicine, University of Troms $\varnothing$, Tromsø, Norway. ${ }^{5}$ School of Medicine and Public Health, University of Newcastle, Newcastle, Australia. ${ }^{6}$ Hunter Area Pathology Service, Hunter New England Area Health, Newcastle, Australia. ${ }^{7}$ The Dutch Cancer Genetics Group, Leiden, the Netherlands. ${ }^{8}$ Hunter Family Cancer Service, Hunter New England Area Health, Newcastle, Australia.

${ }^{9}$ University of NSW, St Vincent's Hospital Clinical School, Sydney, Australia.

${ }^{10}$ Hereditary Cancer Clinic, St Vincent's Hospital, The Kinghorn Cancer Centre, Sydney, Australia. ${ }^{11}$ Department of Pathology, Leiden University Medical Centre, Leiden, the Netherlands. ${ }^{12}$ Dutch Foundation for the Detection of Hereditary Tumours, Leiden, the Netherlands.

Received: 8 May 2013 Accepted: 15 December 2013

Published: 29 December 2013

\section{References}

1. Australian_Institute_of_Health_and_Welfare: Mortality. National Mortality Database 2007. http://www.aihw.gov.au/WorkArea/DownloadAsset.aspx? $i d=6442471324$.

2. Davidson NO: Genetic testing in colorectal cancer: who, when, how and why. Keio J Med 2007, 56(1):14-20.

3. Fearnhead NS, Britton MP, Bodmer WF: The ABC of APC. Hum Mol Genet 2001, 10(7):721-733.

4. Nilbert M, Kristoffersson U, Ericsson M, Johannsson O, Rambech E, Mangell P: Broad phenotypic spectrum in familial adenomatous polyposis; from early onset and severe phenotypes to late onset of attenuated polyposis with the first manifestation at age 72. BMC medical genetics 2008, 9:101.

5. Soravia C, Berk T, McLeod RS, Cohen Z: Desmoid disease in patients with familial adenomatous polyposis. Dis Colon Rectum 2000, 43(3):363-369.

6. Church J, Lynch C, Neary P, LaGuardia L, Elayi E: A desmoid tumor-staging system separates patients with intra-abdominal, familial adenomatous polyposis-associated desmoid disease by behavior and prognosis. Dis Colon Rectum 2008, 51(6):897-901.

7. Lipton $\mathrm{L}$, Tomlinson I: The genetics of FAP and FAP-like syndromes. Fam Cancer 2006, 5(3):221-226.

8. Giardiello FM, Krush AJ, Petersen GM, Booker SV, Kerr M, Tong LL, Hamilton SR: Phenotypic variability of familial adenomatous polyposis in 11 unrelated families with identical APC gene mutation. Gastroenterology 1994, 106(6):1542-1547.

9. Debinski HS, Love S, Spigelman AD, Phillips RK: Colorectal polyp counts and cancer risk in familial adenomatous polyposis. Gastroenterology 1996, 110(4):1028-1030.

10. Crabtree MD, Fletcher C, Churchman M, Hodgson SV, Neale K, Phillips RK, Tomlinson IP: Analysis of candidate modifier loci for the severity of colonic familial adenomatous polyposis, with evidence for the importance of the N-acetyl transferases. Gut 2004, 53(2):271-276. 
11. Nieuwenhuis MH, Vasen HF: Correlations between mutation site in APC and phenotype of familial adenomatous polyposis (FAP): a review of the literature. Critical reviews in oncology/hematology 2007, 61(2):153-161.

12. Cetta F, Dhamo A: Inherited multitumoral syndromes including colorectal carcinoma. Surg Oncol 2007, 16(Suppl 1):S17-23.

13. Wachsmannova-Matelova L, Stevurkova V, Adamcikova Z, Holec V, Zajac V: Different phenotype manifestation of familial adenomatous polyposis in families with APC mutation at codon 1309. Neoplasma 2009, 56(6):486-489.

14. Houlston R, Crabtree M, Phillips R, Tomlinson I: Explaining differences in the severity of familial adenomatous polyposis and the search for modifier genes. Gut 2001, 48(1):1-5.

15. Knudsen AL, Bisgaard ML, Bulow S: Attenuated familial adenomatous polyposis (AFAP): A review of the literature. Fam Cancer 2003, 2(1):43-55

16. Jaeger $\mathrm{E}$, Webb E, Howarth K, Carvajal-Carmona L, Rowan A, Broderick P, Walther A, Spain S, Pittman A, Kemp Z, Sullivan K, Heinimann K, Lubbe S, Domingo E, Barclay E, Martin L, Gorman M, Chandler I, Vijayakrishnan J, Wood W, Papaemmanuil E, Penegar S, Qureshi M, Farrington S, Tenesa A, Cazier JB, Kerr D, Gray R, Peto J, Dunlop M, Campbell H, Thomas H, Houlston R, Tomlinson I: Common genetic variants at the CRAC1 (HMPS) locus on chromosome 15q13.3 influence colorectal cancer risk. Nat Genet 2008, 40(1):26-28.

17. Tenesa A, Farrington SM, Prendergast JG, Porteous ME, Walker M, Haq N, Barnetson RA, Theodoratou E, Cetnarskyj R, Cartwright N, Semple C, Clark AJ, Reid FJ, Smith LA, Kavoussanakis K, Koessler T, Pharoah PD, Buch S, Schafmayer C, Tepel J, Schreiber S, Volzke H, Schmidt CO, Hampe J, Chang-Claude J, Hoffmeister M, Brenner H, Wilkening S, Canzian F, Capella $G$, et al: Genome-wide association scan identifies a colorectal cancer susceptibility locus on 11q23 and replicates risk loci at 8q24 and 18q21. Nat Genet 2008, 40(5):631-637.

18. Tomlinson IP, Webb E, Carvajal-Carmona L, Broderick P, Howarth K, Pittman AM, Spain S, Lubbe S, Walther A, Sullivan K, Jaeger E, Fielding S, Rowan A, Vijayakrishnan J, Domingo E, Chandler I, Kemp Z, Qureshi M, Farrington SM, Tenesa A, Prendergast JG, Barnetson RA, Penegar S, Barclay E, Wood W, Martin L, Gorman M, Thomas H, Peto J, Bishop DT, et al: A genome-wide association study identifies colorectal cancer susceptibility loci on chromosomes 10p14 and 8q23.3. Nat Genet 2008, 40(5):623-630.

19. Broderick P, Carvajal-Carmona L, Pittman AM, Webb E, Howarth K, Rowan A, Lubbe S, Spain S, Sullivan K, Fielding S, Jaeger E, Vijayakrishnan J, Kemp Z, Gorman M, Chandler I, Papaemmanuil E, Penegar S, Wood W, Sellick G, Qureshi M, Teixeira A, Domingo E, Barclay E, Martin L, Sieber O, Kerr D, Gray R, Peto J, Cazier JB, Tomlinson I, Houlston RS: A genome-wide association study shows that common alleles of SMAD7 influence colorectal cancer risk. Nat Genet 2007, 39(11):1315-1317.

20. Houlston RS, Cheadle J, Dobbins SE, Tenesa A, Jones AM, Howarth K Spain SL, Broderick P, Domingo E, Farrington S, Prendergast JG, Pittman AM, Theodoratou E, Smith CG, Olver B, Walther A, Barnetson RA, Churchman M, Jaeger EE, Penegar S, Barclay E, Martin L, Gorman M, Mager R, Johnstone E, Midgley R, Niittymaki I, Tuupanen S, Colley J, Idziaszczyk S, et al: Meta-analysis of three genome-wide association studies identifies susceptibility loci for colorectal cancer at 1q41,3q26.2, 12q13.13 and 20q13.33. Nature genetics 2010, 42(11):973-977.

21. Houlston RS, Webb E, Broderick P, Pittman AM, Di Bernardo MC, Lubbe S, Chandler I, Vijayakrishnan J, Sullivan K, Penegar S, Carvajal-Carmona L, Howarth K, Jaeger E, Spain SL, Walther A, Barclay E, Martin L, Gorman M, Domingo E, Teixeira AS, Kerr D, Cazier JB, Niittymaki I, Tuupanen S, Karhu A, Aaltonen LA, Tomlinson IP, Farrington SM, Tenesa A, Prendergast JG, et al: Meta-analysis of genome-wide association data identifies four new susceptibility loci for colorectal cancer. Nature genetics 2008, 40(12):1426-1435.

22. Crabtree MD, Tomlinson IP, Talbot IC, Phillips RK: Variability in the severity of colonic disease in familial adenomatous polyposis results from differences in tumour initiation rather than progression and depends relatively little on patient age. Gut 2001, 49(4):540-543.

23. Crabtree MD, Tomlinson IP, Hodgson SV, Neale K, Phillips RK, Houlston RS: Explaining variation in familial adenomatous polyposis: relationship between genotype and phenotype and evidence for modifier genes. Gut 2002, 51(3):420-423.

24. Dietrich WF, Lander ES, Smith JS, Moser AR, Gould KA, Luongo C, Borenstein N, Dove W: Genetic identification of Mom-1, a major modifier locus affecting Min-induced intestinal neoplasia in the mouse. Cell 1993, 75(4):631-639.
25. Baran AA, Silverman KA, Zeskand J, Koratkar R, Palmer A, McCullen K, Curran WJ Jr, Edmonston TB, Siracusa LD, Buchberg AM: The modifier of Min 2 (Mom2) locus: embryonic lethality of a mutation in the Atp5a1 gene suggests a novel mechanism of polyp suppression. Genome Res 2007, 17(5):566-576.

26. Silverman KA, Koratkar R, Siracusa LD, Buchberg AM: Identification of the modifier of Min 2 (Mom2) locus, a new mutation that influences Apc-induced intestinal neoplasia. Genome Res 2002, 12(1):88-97.

27. Comelli M, Di Pancrazio F, Mavelli I: Apoptosis is induced by decline of mitochondrial ATP synthesis in erythroleukemia cells. Free Radic Biol Med 2003, 34(9):1190-1199.

28. Seth R, Keeley J, Abu-Ali G, Crook S, Jackson D, llyas M: The putative tumour modifier gene ATP5A1 is not mutated in human colorectal cancer cell lines but expression levels correlate with TP53 mutations and chromosomal instability. J Clin Pathol 2009, 62(7):598-603.

29. Miller SA, Dykes DD, Polesky HF: A simple salting out procedure for extracting DNA from human nucleated cells. Nucleic Acids Res 1988 16(3):1215.

doi:10.1186/1897-4287-11-20

Cite this article as: Talseth-Palmer et al:: The importance of a large sample cohort for studies on modifier genes influencing disease severity in FAP patients. Hereditary Cancer in Clinical Practice 2013 11:20.

\section{Submit your next manuscript to BioMed Central and take full advantage of:}

- Convenient online submission

- Thorough peer review

- No space constraints or color figure charges

- Immediate publication on acceptance

- Inclusion in PubMed, CAS, Scopus and Google Scholar

- Research which is freely available for redistribution

Submit your manuscript at www.biomedcentral.com/submit
C) Biomed Central 